\title{
El estudio de la alimentación a través del análisis de textos fílmicos
}

\author{
Nieves FeBRER FernáNDEZ \\ Universidad de Valladolid \\ nievesfebrer@hotmail.com
}

\begin{abstract}
Resumen:
El objetivo de este artículo es presentar un proyecto de investigación basado en la exploración de una serie de parámetros específicos centrados en el estudio de la alimentación y su desarrollo social, político, tecnológico, económico y artístico. Nuestro eje temático se vertebra en la comprensión de los hábitos humanos relativos al hecho alimentario a través del análisis de textos fílmicos. El cine, ilustra en toda su magnitud narrativa: el conocimiento científico e ideológico de la realidad social. Penetramos a continuación en la selección de películas que nos sirvan de apoyo documental en la búsqueda sociocultural de la alimentación.
\end{abstract}

Palabras clave: alimentación; cultura gastronómica; antropología; ciencias de la comunicación; arte; cine

\section{The study of food through the analysis of film texts}

\begin{abstract}
:
The aim of this article is to present a research project based on the exploration of a number of specific parameters focused on the study of food and its social, political, technological, economic and artistic. Our main theme is structured in understanding human habits related to food made through the analysis of film texts. The film illustrates with the full extent of narrative: scientific knowledge and social reality. We entered below in the selection of films that serve as documentary support in the search for sociocultural food fact.
\end{abstract}

Key Words: Food; food culture; anthropology; communication sciences; art; cinema

\section{Referencia normalizada:}

Febrer Fernández, N. (2014): El estudio de la alimentación a través del análisis de textos fílmicos. Historia y Comunicación Social. Vol. 19. Núm. Especial Enero. Págs. 181-193.

Sumario: 1. Introducción. 1.1. Las prácticas alimentarias. 2. Cometida metodológica. 3. Fundamentos socioculturales de la alimentación. 3.1. Áreas de investigación. 3.1.1. El ritual de la alimentación. 3.1.2. Los sistemas alimentarios. 4. La alimentación a través del cine de ficción. 5. Conclusiones. 6. Referencias bibliográficas. 7. Notas. 


\section{Introducción}

\subsection{Las prácticas alimentarias}

Los objetivos principales de esta propuesta se centran en mostrar el concepto de la alimentación en su pluralidad cultural, describiendo para ello su enorme complejidad en cuanto a los sistemas, el desarrollo tecnológico y los aspectos culturales, históricos y económicos. Nuestro propósito es estudiar, pues, las características técnicas, simbólicas, estéticas, formales y estructurales de los rituales de socialización, permitiéndonos así aproximarnos al lenguaje artístico y a los imaginarios socioculturales de la alimentación a través del cine de ficción ${ }^{1}$.

Nuestra investigación se justifica en el hecho de que en la actualidad se celebran una gran variedad de ferias gastronómicas, eventos, concursos, premios y festivales dedicados al cine y la gastronomía ${ }^{2}$. Junto a éstos, se desarrollan cada día importantes jornadas y seminarios sobre cocina y alimentación destinados al encuentro nacional e internacional de mercados, productos y/o recetas. La expansión de los recursos tecnológicos y, por ende, el amplio campo de información trasmitido a través de los medios de masas, convierten la cultura gastronómica en un espectáculo mediático a nivel social que ha reconfigurado, a su vez, las políticas culturales (García Canclini, 1997).

Existen numerosas investigaciones que han señalado la alimentación como un poderoso vehículo de transmisión de ideas, estilos e intercambios culturales. Cada una de estas tipologías fortalece el conocimiento del individuo y la identidad social. Así pues, los fenómenos alimentarios que surgen en diversos contextos culturales son el resultado de elaborados procesos simbólicos expresivos que identifican a un grupo social a través de categorías.

El léxico de la alimentación consiste en el repertorio de los productos alimentarios disponibles, cuyas unidades son indicadoras de opciones culturales, gustos sociales, recursos territoriales o relaciones comerciales y económicas. Los alimentos, por lo tanto, cumplen una función nutricional imprescindible para el organismo, pero cada cultura utiliza un lenguaje diferente en los modos de "hacer", manipular o preparar elementos culinarios, siendo éstos el resultado de un proceso cultural al que se le ha otorgado histórica y socialmente un valor simbólico y comunicativo (Montanari, 2004). Para el universalmente citado Claude Lévi-Strauss (1987), estas categorías culinarias instituyen, consecuentemente, un lenguaje análogo con la cocina, cuyos contenidos que se le asignan son propios de cada sociedad, colectivo, grupo, región, etc. Es decir, todos hablamos una lengua, pero cada una de ellas es distinta.

Así por ejemplo, las anticuadas diferencias entre clases dominantes (cultura aristocrática) y dominadas (cultura campesina), se encuentran aún hoy en relación con la cocina rica o la cocina pobre; o lo que podríamos llamar alta o baja cocina. Con todo, son varios los autores que han hecho mención a la huella tan importante que ha dejado la cocina pobre sobre las clases altas; $y$ ambas, hoy por hoy, se han beneficiado mutuamente de su existencia, enriqueciendo platos y recetas. El lujo y la ostentación 
alimentaria marcaban distintos comportamientos de clase y la abundancia de comida señalaba una situación privilegiada a quien la poseyera. Durante el transcurso del siglo XIX al XX, sin embargo, comer mucho deja de ser un privilegio que implicará cambios a su vez en la ideología y el imaginario gastronómico colectivo. A principios del siglo pasado, las personas delgadas comienzan a ser consideradas bellas, introduciendo un nuevo concepto corporal desconocido hasta la fecha, ya que en la mayoría de las sociedades tradicionales comer con apetito era una práctica positivamente valorada y las mujeres gruesas se percibían más atractivas sexual y socialmente.

Nos adentramos de esta forma en un nuevo aprendizaje corporal desnaturalizado y disciplinado, tal y como han manifestado varios autores, entre ellos, el teórico Michel Foucault (2001), quien demostró como las instituciones muestran un afán de regulación hacia el cuerpo mediante el uso del poder y del control. Desde finales del XIX, limitarse en el consumo alimentario aporta distinción, delicadeza y buenas maneras entre las clases altas. El cuerpo se convierte en un reclamo ético redibujado a través de la autodisciplina, el autocontrol y la sobriedad. Al mismo tiempo, debido al nacimiento de la cultura visual y de los nuevos cánones de la moda, aparecen nuevos modelos oníricos que imponen el sueño de la delgadez, la belleza, el atractivo sexual y la juventud como sinónimos de amor, éxito, triunfo y felicidad.

Dicho esto, subrayamos la necesidad de introducirnos detenidamente en los procesos gastronómicos actuales a través de la selección de películas que nos sirvan de apoyo documental.

\section{Cometida metodológica}

Las pautas metodológicas que organizan nuestro trabajo incluyen los usos interpretativos de las ciencias de la comunicación, las ciencias sociales en general y de la antropología de la alimentación en particular. Para alcanzar los objetivos planteados, realizaremos, primero, un estudio en el que investigaremos descriptivamente el fenómeno de la alimentación a partir de la revisión de la literatura técnica; y en segundo lugar, analizaremos los discursos cinematográficos, recurriendo a textos fílmicos.

\section{Fundamentos socioculturales de la alimentación}

\section{1. Áreas de investigación}

A continuación vamos a desglosar los parámetros principales que vertebran nuestro programa en las siguientes líneas de investigación: 


\subsubsection{El ritual de la alimentación}

Nuestra propuesta desarrolla sus fundamentos socioculturales en el ámbito de las reglas de comensalía, siendo aquéllas que definen las prácticas y comportamientos en los banquetes públicos o políticos, ya que representan las jerarquías existentes dentro de los grupos sociales. Los primeros manuales (siglo XII), se destinaron en sus orígenes a difundir estas normas entre la aristocracia, excluyendo por lo tanto de la mesa señorial a personas campesinas. Hasta el siglo XVII, que es cuando la clase burguesa comienza a adoptar las modas y los gustos de la corte aristocrática, no podemos hablar de una unificación en los buenos modales, en las técnicas de preparación de los alimentos, en la instrucción en el uso de los cubiertos o en la colocación de los platos.

Los gustos alimentarios se basan pues al menos en cuatro tipos de factores: biológicos, psicológicos, culturales y sociales. El gusto es un aprendizaje, cuyas aversiones innatas pueden ser modeladas o incluso invertidas por la influencia social o por la inmersión en una cultura. En este sentido, Pierre Bourdieu enfoca buena parte de sus investigaciones en establecer los efectos de la cultura sobre las prácticas sociales. En su libro La distinción (1988), estudia el gusto como uno de los fenómenos más indóciles en el análisis sociocultural, y orienta su discurso en la dialéctica existente entre acción y estructura, demostrando que el gusto puede relacionarse con la semiología como si fuese un sistema de signos del lenguaje. Estos signos, pertenecen a diferentes hábitos alimentarios. De esta manera, son importantes los estilos de vida, las relaciones entre alimentación, salud e imagen corporal; así como las adaptaciones sociales, los desplazamientos territoriales, las culturas locales, los modelos de aculturación o los condicionantes socioeconómicos y sociopolíticos.

En definitiva, siendo la mesa una metáfora de la vida, el banquete instituye así las relaciones formales existentes en una cultura determinada, e ilustra las diplomacias subyacentes alrededor de ésta, mostrando por ejemplo qué se come, cómo se come $\mathrm{y} / \mathrm{o}$ el lugar donde se sientan los comensales en torno a un jefe o persona insigne ${ }^{3}$.

Ingerir un alimento es llegar pues a un tejido común de evocaciones, connotaciones y significaciones. Es en la ritualidad cotidiana, donde las reglas adquieren importantes significados semióticos capaces de definir la identidad individual y social. En suma, la alimentación no sólo representa la pertenencia a un grupo, sino las identidades afectivas en el mismo. Esto es, nos nutrimos de alimentos, pero también de lo imaginario. El alimento, por tanto, es un sistema de comunicación vinculado a una serie de imágenes, cuyo ritual señala las situaciones y las conductas adquiridas. La alimentación, decíamos, es un signo polisémico, cuya unidad funcional explicita un orden basado en satisfacer el hambre, nutrir el cuerpo, extender las relaciones sociales, simbolizar experiencias emocionales y estatus sociales (Contreras Hernández \& Gracia Arnaiz, 2005) 


\subsubsection{Los sistemas alimentarios}

Los sistemas alimentarios, entendidos éstos por un conjunto de normas, comportamientos, valores e imaginarios que caracterizan la elección, preparación y consumo de los alimentos; hacen referencia al hecho de que el ser humano es fundamentalmente omnívoro, aunque esto no significa que coma de todo, sino que elige su comida siguiendo criterios técnicos y simbólicos asociados a la misma. Podemos destacar a este respecto las aportaciones realizadas ente otros por los antropólogos Mary Douglas (1973) y Marvin Harris (1989) sobre lo que es y lo que no es comestible, según intervengan consideraciones religiosas, preferencias, tabúes, etc. La alimentación es, pues, un producto cultural racionalizado y transmitido a través de generaciones.

Llegados a este punto, es un supuesto básico sostenido por los investigadores que el ser humano, tal y como hemos señalado, transforma los alimentos a través de la tecnología y no come lo que se encuentra en la naturaleza sin más. En la literatura científica, se ha hecho un especial hincapié en relacionar la conquista del fuego con el nacimiento de la civilización humana. Cocinar, trajo consigo mejoras en el plano cognitivo, físico y psíquico de los individuos. El biólogo Faustino Cordón (2009), apunta: "En este primer estadio, según las investigaciones antropológicas, el hombre aún no habia aprendido a cocinar, ni casi a hablar, las condiciones objetivas para el descubrimiento de la cocina, aunque con toda probabilidad nunca llegue a precisarse cómo, cuándo y con qué producto vegetal o animal verificó el transcendente hallazgo".

El fuego en sus inicios ayudó al hombre a protegerse de los depredadores en las noches oscuras proporcionándole a su vez calor. Con el tiempo, a partir de un incipiente y precario conocimiento mecánico, a través del cual una reacción química produce una combustión en la leña quemada, permitió el comienzo de la cocina. La transformación de un material orgánico en forma de alimento, sugiere a la comunidad científica que el hombre evolucionó de manera significativa en el hecho no sólo de buscar comida, sino de prepararla y cocinarla. Esta práctica transcendental pasó a constituir la fuente energética de la primera actividad artificial hecha en cooperación y en grupo, dando origen a la palabra y al poder de comunicar, enunciar y comprender acciones y experiencias. Otros inventos, como la cerámica y ciertos útiles y herramientas, permitieron también la cocción de los alimentos, aportando ventajas importantes.

Aun así, existen diferentes tipos de cocina que no coinciden específicamente con esta idea. La cocina japonesa o china, no precisa del fuego en la preparación del pescado crudo. Igualmente, las condiciones económicas y el acceso al combustible o a la industria, determinan comportamientos alimenticios que tienen que ver con la forma en la que se ingieren los alimentos. Hoy día, por ejemplo, la cocina de vanguardia o la nouvelle cuisine, objeto de nuestro interés, ha añadido nuevas técnicas y procedimientos en perpetuo cambio, crecimiento e investigación de texturas, alteraciones, acumulaciones, formas, sabores, perdurabilidad, etc.: Así, "la comidas se 
han diversificado considerablemente en diferentes aspectos dando lugar a innovaciones, adaptaciones, sustituciones y desapariciones de productos, recetas o prácticas" (Gracia Arnaiz, 2008)

Finalizando este epígrafe, los soportes empíricos que sustentan nuestro estudio desvelan la enorme complejidad a la que nos enfrentamos en esta propuesta normativa: la alimentación, habida cuenta, es un elaborado proceso cultural tanto en los modos de producción y distribución, como en los modelos de consumición: sumándose en las últimas décadas importantes innovaciones en la alimentación humana, trasladándose ésta desde el ámbito doméstico y artesanal hacia estructuras industriales centradas en el consumo masivo y en los sectores agroalimentarios de conservación, distribución y restauración.

\section{La alimentación a través del cine de ficción}

Iniciamos la segunda parte de nuestro artículo señalando las relaciones existentes entre alimentación y cine. Nos adentramos así en el fenómeno sociocultural de la alimentación a partir del análisis del contenido en el discurso cinematográfico. A lo largo de estas páginas, penetraremos en la expresividad del lenguaje del cine, mostrando el hecho alimentario que reside en su temática.

El cine, el arte y los relatos producidos por las personas, constituyen una fuente de información fundamental, ya que aportan conocimiento científico, técnico, ideológico, estético e ilustrativo sobre la realidad social que nos rodea, tanto en los procesos de creación como en los contextos históricos en los que fueron concebidos. Hablamos así de un objeto cultural fabricado y construido bajo una lógica concreta de pensamiento. El estudio antropológico de obras escritas, pictóricas o fílmicas, ha localizado su interés en la producción visual como un sistema ordenado en la comunicación humana, aspecto este último incuestionable en el desarrollo teórico de nuestra investigación. En todas las sociedades, señala Lourdes Méndez (2003), existen diferentes formas de expresión artística que implican prácticas, habilidades técnicas o saberes específicos que son apreciados de una determinada manera y que poseen ciertas funciones estéticas. Néstor García Canclini (2010), agrega: "tal vez la gastronomía y la estética son dos de las zonas donde el trabajo antropológico está más obligado a reconocer entrelazamientos interculturales".

El medio fílmico, contiene interrelaciones varias de elementos (signos icónicos, sonoros, gestuales y verbales) junto con una serie de articulaciones discursivas (montaje, movimiento de cámara, etc.), siendo el resultado un artefacto textual estructurado en una narrativa compleja. Toda imagen, equivale a un hecho cultural que transmite mensajes multidireccionales portadores de un significado estético, simbólico y social en el proceso de elaboración y lectura, tanto en los contenidos, como la forma en la que se expresan a partir de la exploración de los parámetros significativos que los integran. De hecho, numerosos países han basado su formación 
cultural y política a través del cine, tal y como ha afirmado el historiador Marc Ferro (1995), provocando arquetipos culturales y nuevas interpretaciones y reconfiguraciones. Así, los imaginarios socioculturales hacen emerger contenidos significativos para la vida de los hombres, permitiéndoles, asimismo, crear nuevas comunicaciones sociales (Solares, 2006). Contribuyen a la integración social, otorgando sentidos poéticos a nuestros procesos vitales.

Así, de acuerdo con los principios anteriores, el cine actúa como un elemento imaginario individual y colectivo, aspecto profusamente trabajado en la ciencia antropológica. El lenguaje cinematográfico, esgrime un valor testimonial cuyas cualidades estéticas presuponen una herramienta indispensable de conocimiento.

Con este fin retomamos los objetivos propuestos al inicio, quedando suficientemente demostrado que el cine configura el imaginario colectivo. Sin embargo, son escasas las películas que no reflejen de alguna forma el hecho sociocultural de la alimentación, ya que ésta está presente en todos los ámbitos humanos y, por lo tanto, no terminaríamos de enumerar una serie de films que bien pudieran encuadrarse en este epígrafe. Nuestro cometido en este artículo es, pues, limitado, centrándonos en aquellas categorías temáticas que señalan la alimentación como parte significativa de su discurso.

La alimentación cinematográfica, nos llega a través de las primeras imágenes documentales de los hermanos Lumière (Repas de bébé, 1895) y de la innovadora película de James Williamson, The Big Swallow, quien en 1901 creó un personaje que avanza hacia la cámara abriendo desmesuradamente la boca hasta devorar de manera figurada toda la pantalla, simbolizando que el hecho culinario va unido al consumo fílmico.

Pocos años después, el cine de posguerra se hizo eco de la naturaleza del hambre ejemplificada en La quimera del oro (The Gold Rush, Charles Chaplin, 1925), cuya expresión culminante se desarrolla en la famosa secuencia en la que el personaje emblemático de Charlot-su alter ego- cocina y come una bota (enrollando los cordones como si fuesen espaguetis) o haciendo bailar a dos panecillos manifestando su aislamiento y soledad. Características similares las encontramos en Una noche en la ópera (A Night at the Opera, Sam Wood, 1935), donde los hermanos Marx exhiben su pobreza en la paradigmática y divertida escena del camerino, cuando le piden al camarero, una y otra vez, que les traiga comida, asentando en la mente del espectador la miseria de los personajes protagonistas.

El cine, en suma, nos ha mostrado a través de su magia y belleza simbólica, épocas y momentos cruciales sobre el hambre y la miseria. Recuérdese por ejemplo la película Lo que el viento se llevó (Gone With the Wind, Víctor Fleming, 1939), cuya protagonista Scarlett O'Hara (personaje interpretado por la actriz Vivien Leigh) alza su puño desafiante al cielo en uno de los momentos y escenas más inmortalizadas de la historia del cine, exponiendo su firmeza a sobrevivir tras la Guerra de Secesión estadounidense. 
Por el contrario, la comida como símbolo de ostentación y estatus social entre la nobleza, encuentra un destacado referente en películas como María Antonieta (Marie-Antoinette, Sofía Coppola, 2006) cuya lectura nos permite descifrar la opulencia emocional y física de sus personajes; al igual que en Vatel (Roland Joffé, 2000), biopic del prestigioso chef durante el reinado de Luis XIV, que organizaba grandiosas y suntuosas fiestas para favorecer los placeres de los nobles, además de enormes cenas compuestas por ochenta platos, treinta mesas de buffet y cinco servicios distintos de faisanes, codornices, perdices, etc. Los manjares se servían en una vajilla de oro creada expresamente para la familia real, simbolizando la idealizada cúspide de la corte (Calero Ruiz, 2011)

$\mathrm{El}$ arte, pues, del comer hedonista, relacionado con el placer y el disfrute, se cierne en las sensaciones del propio cuerpo y se manifiesta en numerosos films, entre otros, La vida privada de Enrique VIII (The Private Life of Henry VIII, Alexander Korda, 1933) en la que se representa una ennoblecida Inglaterra del siglo XVI, Viridiana (Luís Buñuel, 1961) o en La gran comilona (La Grande Bouffe, Marco Ferreri, 1973) cuya contenido central nos lleva hacia los apetitos de la carne, la lujuria, la gula y, finalmente, la muerte.

Las reglas de comensalía que hemos definido anteriormente, sugieren asimismo que la alimentación establece importantes relaciones socioculturales. Comer en soledad tiene una clara connotación negativa, según la teoría antropológica. El componente de interacción es el que reactualiza y redibuja el comportamiento normativo y los vínculos sociales, por lo tanto, la comida pierde sentido si se realiza desacompañado (Díaz-Méndez, 2008). Estas ideas se muestran en películas como El padrino (The Godfather, Francis Ford Coppola, 1972) reflejando la ritualización familiar e identitaria de culturas; o en Como agua para chocolate (Alfonso Arau, 1992), inspirada en el México de principios del siglo XX, donde la gastronomía es una compañera de viaje a partir de la cual los protagonistas expresan dramáticamente sus sentimientos; o en Comer, beber, amar (Eat Drink Man Woman, Ang Lee, 1994) donde las relaciones se forjan alrededor de una mesa, ilustrando las diferentes generaciones a partir de un saber ancestral culinario.

Como ya hemos comentado, la alimentación es un complicado cuerpo de imágenes, comportamientos, sistema de signos y protocolos de actuación. Por esto mismo, la alimentación es igualmente un elemento señalado en las fiestas, los ritos y las ceremonias en todas las sociedades y culturas. Una fiesta, tanto sea secular o religiosa, exige una alimentación especializada, menos frecuente y generalmente más cara, que difiere de los días ordinarios. Estas costumbres, están extendidas tanto en los momentos vitales de los ciclos de la vida (nacimientos, cumpleaños, matrimonio...) como en celebraciones históricas según distintos calendarios. Son alimentos, a su vez, que denotan ellos mismos la festividad, posición que ocupan las castañas, el marisco, el cordero o los postres especiales como el pudín, tal y como se refleja en Dublineses (The Dead, John Huston, 1987), película que transcurre durante la noche de navidad de 1904 en Dublín. 
Asimismo, todas las religiones, decíamos, rigen la alimentación de una u otra manera mediante la restricción y la disminución, en la mayoría de los casos, del placer de comer, como podemos ver en El festín de Babette (Babette's Feast, Gabriel Axel, 1987) inspirada en la novela homónima de Isak Dinesen y ambientada en el siglo XIX en Dinamarca, donde el gozo y el disfrute no forman parte de la estricta educación de sus protagonistas. Sin embargo, es tal la fuerza seductora de las viandas y la gastronomía que, "poco a poco, en un ceremonial extenso y emotivo, los personajes protagonistas van cediendo a la sensualidad de la cocina francesa" (Torres Pancorbo, 2011).

Las películas han resignificado igualmente la restitución de los sentidos a través de los alimentos. Una tienda de chocolates y bombones desencadena en una pequeña población la liberación de sus habitantes, donde los tabúes alimentarios son el telón de fondo de la represión y del temor en Chocolat (Lasse Hallström, 2000), film que se desenvuelve en una confluencia de placeres, simbolizados a partir de la alimentación.

Para finalizar, requiere nuestra atención la nueva cocina de vanguardia, cuyos orígenes se remontan a finales de los años sesenta y principios de los setenta, condicionada por una época en la que se producen amplios cambios artísticos, sociales y económicos en Europa. La gastronomía sintonizó, pues, con muchas de estas nuevas olas artísticas. Los críticos gastronómicos Henri Gault y Christian Millau, pioneros en este ámbito, formularon en el artículo "Vive la nouvelle cuisine francaise - Voici ses dix commandements" (1973), los conceptos de innovación, invención y creación como parte de los valores y las virtudes culinarias. Estos mecanismos, generaron tendencias nuevas en el mercado del turismo, la hostelería y la cocina.

El cine se ha encargado de mostrarnos estas ideas en el trabajo de cocineros ilustres, como por ejemplo en American cuisine (Jean-Yves Pitoun, 1999); Deliciosa Martha (Bella Martha, Sandra Nettelbeck, 2000); Woman on Top (Fina Torres, 2000); Un toque de canela (A Touch of Spice, Tassos Boulmetis, 2003); Sin reservas (No reservations, Scott Hicks, 2007); Ratatouille (Brad Bird, 2007); Estómago (Marcos Jorge, 2007); Fuera de carta (Nacho G. Velilla, 2008); The Ramen Girl (Robert Allan Ackerman, 2008); Julie \& Julia (Nora Ephron, 2009); El chef (Comme un Chef, Daniel Cohen, 2012) o La cocinera del presidente (Les saveurs du Palais, Christian Vincent, 2012), película esta última que nos cuenta la historia de la prestigiosa chef Hortense Laborie (Catherine Frot), que trabajó durante los años de mandato de François Miterrand en el Palacio del Elíseo.

\section{Conclusiones}

En conclusión, las prácticas alimentarias suponen la existencia de una serie de protocolos de actuación, costumbres, situaciones y conductas en las que se desarrollan las condiciones propias de la comunicación humana. Cine y gastronomía, es 
una unión que enriquece los imaginarios socioculturales, reflejando experiencias y definiendo identidades.

El estudio de obras escritas, pictóricas o fílmicas, es un instrumento incuestionable en el desarrollo teórico de nuestra investigación. El cine constituye una fuente de información fundamental que aporta conocimiento científico, técnico, ideológico, estético e ilustrativo sobre la realidad social que nos rodea. Los textos fílmicos son un artificio creador de múltiples sentidos que, como tales, dan forma y contenido a las imágenes simbólicas y lingüísticas subyacentes que intervienen en la cultura, tanto en la manera en la que se expresan como en la exploración de los parámetros significativos que los integran.

\section{Bibliografía}

BOURDIEU, Pierre (1988). La distinción. Criterios y bases sociales del gusto. Madrid: Taurus.

CALERO RUIZ, Clementina (2011). "Vatel y otros arquitectos de sueños efímeros. Banquetes, sentidos y triunfi en las cortes europeas de la época moderna". En Revista Latente. Revista de historia y estética del audiovisual, $\mathrm{n}^{\circ}$ 9, pp. 45-58

CONTRERAS HERNÁNDEZ, Jesús \& GRACIA ARNÁIZ, Mabel (2005). Alimentación y cultura. Perspectivas antropológicas. Barcelona: Ariel.

CORDÓN, Faustino (2009). Cocinar hizo al hombre. Barcelona: Tusquets Editores.

DÍAZ-MÉNDEZ, Cecilia (2008). “¿Qué significa comer bien?”. En Distribución y consumo. Año 18. $\mathrm{n}^{\circ}$ 97, pp. 28-37

DOUGLAS, Mary (1973). Pureza y peligro. Un análisis de los conceptos de contaminación y tabú. Madrid: Siglo XXI.

FERRO, Marc (1995). Historia contemporánea y cine. Barcelona: Ariel.

FOUCAULT, Michel (2001). "El sujeto y el poder". En Brian Wallis (ed.). El arte después de la modernidad (nuevos planteamientos en torno a la representación). Madrid: Akal.

GARCÍA CANCLINI, Néstor (1997). Cultura y comunicación: entre lo global y lo local. Buenos Aires: Ediciones de Periodismo y Comunicación Social.

GARCÍA CANCLINI, Néstor (2010). "De la comida al monumento: lo intercultural más allá de los rituales". En Catálogo de la exposición de Antoni Miralda. Madrid: Museo Reina Sofía.

GRACIA ARNAIZ, Mabel (2008). "Nuevas maneras de vivir, nuevas maneras de comer". En Distribución y consumo, Año no 18, nº 97, pp. 5-17

HARRIS, Marvin (1989). Bueno para comer. Enigmas de alimentación y cultura. Madrid: Alianza.

LÉVI-STRAUSS, Claude (1987). El origen de las maneras de mesa. México. Siglo XXI. 
MÉNDEZ, Lourdes (2003). La antropología ante las artes plásticas. Aportaciones, omisiones, controversias. Madrid: Siglo XXI.

MONTANARI, Massimo (2004). La comida como cultura. Gijón: Trea.

SOLARES, Blanca (2006). "Aproximaciones a la noción de imaginario". En Revista mexicana de ciencias políticas y sociales, $\mathrm{n}^{\circ}$ 198. pp. 129-144

TORRES PANCORBO, Pedro Ángel (2011). Cine y gastronomía. Madrid: Vision Libros.

\subsection{Textos fílmicos}

ARAU, Alfonso (1992): Como agua para chocolate. Mexican Film Institute. México. AXEL, Gabriel (1987): Babette's Feast. Nordisk Films / Panorama Film International / DFI. Dinamarca.

BIRD, Brad (2007): Ratatouille. Pixar Animation Studios / Walt Disney Pictures. Estados Unidos.

BOULMETIS, Tassos (2003): A Touch of Spice. Greek Film Center / Filmnet / Cinegram. Grecia.

BUÑUEL, Luis (1961): Viridiana. Coproducción España-México; Films 59 / UNINCI / Producciones Alatriste. España.

CHAPLIN, Charles (1925): The Gold Rush. United Artists. Estados Unidos.

COHEN, Daniel (2012): Comme un Chef. Coproducción Francia-España; Gaumont. Francia.

COPPOLA, Sofía (2006): Marie-Antoinette. Columbia Pictures. Estados Unidos.

DEMME, Jonathan (1991): The Silence of the Lambs. Orion Pictures. Estados Unidos.

EDWARDS, Blake (1968): The Party. Warner Bros. Pictures. Estados Unidos.

EPHRON, Nora (2009): Julie \& Julia. Columbia Pictures / Scott Rudin Productions. Estados Unidos.

FERRERI, Marco (1973): La Grande Bouffe. Coproducción Francia-Italia; Mara Films / Les Films 66 / Capitolana Films. Francia.

FLEMING, Victor (1939): Gone With the Wind. Selznick International Pictures / Metro-Goldwyn-Mayer (MGM). Estados Unidos.

FORD COPPOLA, Francis (1972): The Godfather. Paramount Pictures / Albert S. Ruddy Production. Estados Unidos.

HALLSTRÖM, Lasse (2000): Chocolat. Miramax International. Reino Unido.

HICKS, Scott (2007): No reservations. Castle Rock Entertainment / Village Roadshow Pictures. Estados Unidos.

HUSTON, John (1987): The Dead. Coproducción Reino Unido-Irlanda-Estados Unidos; Channel 4 / Delta Film / Liffey Films / Vestron Pictures / Zenith Entertainment. Reino Unido.

JEUNET, Jean-Pierre \& CARO, Marc (1991): Delicatessen. UGC / Hachette Première. Francia.

JOFFÉ, Roland (2000): Vatel. Coproducción GB-Francia. Reino Unido.

JONES, Terry \& GILLIAM, Terry (1983): The Meaning of Life. Universal Pictures. Reino Unido. 
JORGE, Marcos (2007): Estómago. Coproducción Brasil-Italia; Zencrane Filmes / Indiana Production Company. Brasil.

KORDA, Alexander (1933): The Private Life of Henry VIII. London Films. Reino Unido.

LEE, Ang (1994): Eat Drink Man Woman. Central Motion Pictures / Ang Lee Productions / Good Machine Productions. Taiwán.

LUMIÈRE, Louis (1895): Repas de bébé. Lumière. Francia.

MARTÍN CUENCA, Manuel (2013): Caníbal. Coproducción España-Rumanía-Rusia-Francia; La Loma Blanca / Mod Producciones / CTB Film Company / Libra Film / Luminor.

MARSHALL, Frank (1993): Alive!. Touchstone Pictures / Paramount Pictures / Kennedy/Marshall Production. Estados Unidos.

NETTELBECK, Sandra (2001): Bella Martha. Bavaria Film International. Alemania. PITOUN, Jean-Yves (1999): American cuisine. Les Films Balenciaga / M6 Films / PolyGram Audiovisuel. Francia.

SCOTT, Ridley (1979): Alien. 20th Century Fox / Brandywine Productions. Estados Unidos.

TORRES, Fina (2000): Woman on Top. Fox Searchlight Pictures. Estados Unidos.

VELILLA, Nacho G. (2008): Fuera de carta. Ensueño Films / Antena 3 Films / Canguro Producciones. España.

VINCENT, Christian (2012): Les saveurs du Palais. Armada Films / Vendôme Production / Armada Films Production. Francia.

WILLIAMSON, James (1901): The Big Swallow. Williamson Kinematograph Company. Reino Unido.

WOOD, Sam (1935): A Night at the Opera. Metro-Goldwyn-Mayer. Estados Unidos.

\section{Notas}

1 Parte de este estudio es el resultado de una investigación reciente presentada en el I Congreso Avances en la Investigación Científica, Universidad Camilo José Cela, Campus Madrid-Villafranca, 11 de Julio de 2013.

2 Podemos destacar en nuestro país, entre otros, la sección Culinary Cinema en el Festival de cine de San Sebastián (y organizada conjuntamente por Basque Culinary Center y Zinemaldia); Film \& Cook que se celebra en Madrid y Barcelona; el Festival Cinegourland en Vizcaya; o Cine es Cena, cuya proyección se da anualmente en la Ciudad de La Laguna.

3 Por esta misma razón, es costumbre en sociedades más modernas la presencia de la mesa redonda que elimina las jerarquías sociales. 


\section{La autora}

Nieves Febrer Fernández ha sido profesora de Grado y Postgrado en Análisis del discurso cinematográfico, Arte Contemporáneo e Investigación y Metodología por las Facultades de Filosofía y Letras (UVa) y Ciencias de la Comunicación (UCJC). Ha publicado artículos en revistas científicas especializadas sobre antropología, arte y cine; y es Doctora en Comunicación Audiovisual (UVa), Diploma en Estudios Avanzados en Historia del Arte Contemporáneo (UCM), Licenciada en Bellas Artes (UCM) y Licenciada en Antropología Social y Cultural (UCM). 